\title{
Hepatocellular carcinoma treatment strategies - a case-based review
}

\author{
Rute Alves ${ }^{1}$, Manuel Teixeira Gomes ${ }^{2}$, Carlos Sampaio Macedo², Helena P. Miranda ${ }^{3,4,5}$, Filipe \\ Nery $^{3,4,5}$ \\ 1. Centro Hospitalar do Porto - Hospital Santo António, Internal Medicine Department, Portugal. 2. Centro Hospitalar do \\ Porto - Hospital Santo António, Radiology Department, Portugal. 3. Centro Hospitalar do Porto - Hospital Santo António, \\ Hepato-Pancreatic Transplantation Unit, Portugal. 4. EpiUnit - Instituto de Saúde Pública da Universidade do Porto, \\ Portugal. 5. Instituto de Ciências Biomédicas de Abel Salazar, Universidade do Porto, Portugal.
}

Correspondence: Largo Prof. Filipe Nery. Address: Abel Salazar S/N 4099-001 Porto, Portugal.

Email: filipegaionery@gmail.com

Received: June 2, 2015

DOI : $10.5430 /$ jst.v5n2p120
Accepted: August 4, $2015 \quad$ Online Published: September 15, 2015

URL: http://dx.doi.org/10.5430/jst.v5n2p120

\section{Abstract}

Hepatocellular carcinoma (HCC) is one of the most common tumors worldwide and one of the fastest growing causes of cancer-related mortality, being mostly diagnosed in patients with cirrhosis. Despite the recent efforts regarding an earlier diagnosis, the majority of patients are at advanced stages at first presentation, when the potential for institution of curative strategies is scarce. This tumor is remarkable because it occurs mostly superimposed on chronic liver diseases, which entails the need to take special attention to liver function preservation and hepatotoxicity prevention when choosing a specific therapy. Major changes had occurred in the management of HCC in the last decade. The decision-making process must be based on an accurate staging of the patient, using the Barcelona Clinic Liver Cancer (BCLC) staging system, updated knowledge of the new therapeutic options, their contraindications and the potential local or systemic complications. The authors start from 4 clinical different scenarios, in order to objectively discuss the therapeutic options available and the decision-making-process based on the staging system.

\section{Key words}

Hepatocellular carcinoma, Barcelona Clinic Liver Cancer staging classification, Liver transplantation, Percutaneous ablation, Transarterial chemoembolization

\section{I ntroduction}

Hepatocellular carcinoma (HCC) is a major global health problem, being the primary malignancy of the liver (represents more than $90 \%$ of primary liver cancers), one of the most common tumors worldwide and one of the fastest growing causes of cancer-related death ${ }^{[1,2]}$. The most recent data shows that HCC is the seventh most common cancer $(5.6 \%$ of all cases) and the second cause of cancer-related death ( $9.1 \%$ of all cases) worldwide. HCC is rarely diagnosed in patients without chronic disease of the liver. The age-adjusted incidence increased over the past 20 years in western countries and, specially, in less developed regions (Southeast Asia and sub-Saharan Africa) - accounting for $83 \%$ of all new cases ${ }^{[3]}$. Despite the widespread implementation of surveillance programs in patients with cirrhosis, more than half of the patients 
with HCC are diagnosed late, when curative treatments cannot be applied ${ }^{[4]}$. There is also the problematic of recurrence after implementation of curative strategies, which still affects a big proportion of patients ${ }^{[5,6]}$.

It is thus understandable that, in the last decade, there have been several clinical and scientific advances concerning diagnosis and therapeutic strategies for HCC, bringing together efforts of several scientific associations with the purpose of establishing recommendations that could properly assist clinicians in the decision-making process ${ }^{[1,7-11]}$.

Long-term disease-free survival relies on HCC's early detection and treatment institution. Since the population at risk is identified, all scientific associations recommend regular ultrasound screening in at-risk patients, with a 6-month interval gathering consensus and being more cost effective than a 3-month interval ${ }^{[12]}$. Tumor markers like $\alpha$-fetoprotein do not have clinical value for screening and diagnosis, and novel biomarkers for early $\mathrm{HCC}$ are needed ${ }^{[7,13]}$, as they may improve the current effectiveness of screening.

The treatment is based on the tumor stage, patient performance status and liver function reserve and requires a multidisciplinary approach. Resection, liver transplantation, percutaneous ablation techniques (mainly radiofrequency), transarterial ablation techniques (mainly chemoembolization) and systemic targeted agents are the current available treatment options. For practical purposes, HCC treatment strategies are categorized as curative, palliative or symptomatic, depending upon the tumor features, hepatic function reserve, presence of extra-hepatic disease or vascular invasion ${ }^{[14]}$.

Staging of the disease is then crucial in selecting the best therapeutic approach, based on predicted prognosis. Out of all the multiple staging systems, the Barcelona Clinic Liver Cancer (BCLC) staging system is the only one that incorporates tumor burden, liver function assessment and performance status in the disease stage ${ }^{[1,15,16]}$, being the most externally validated system $^{[1,16]}$. This classification divides patients in 5 stages [very early (0), early (A), intermediate (B), advanced (C) and terminal (D)] providing simultaneously prognostic and treatment allocation information (see Figure 1).

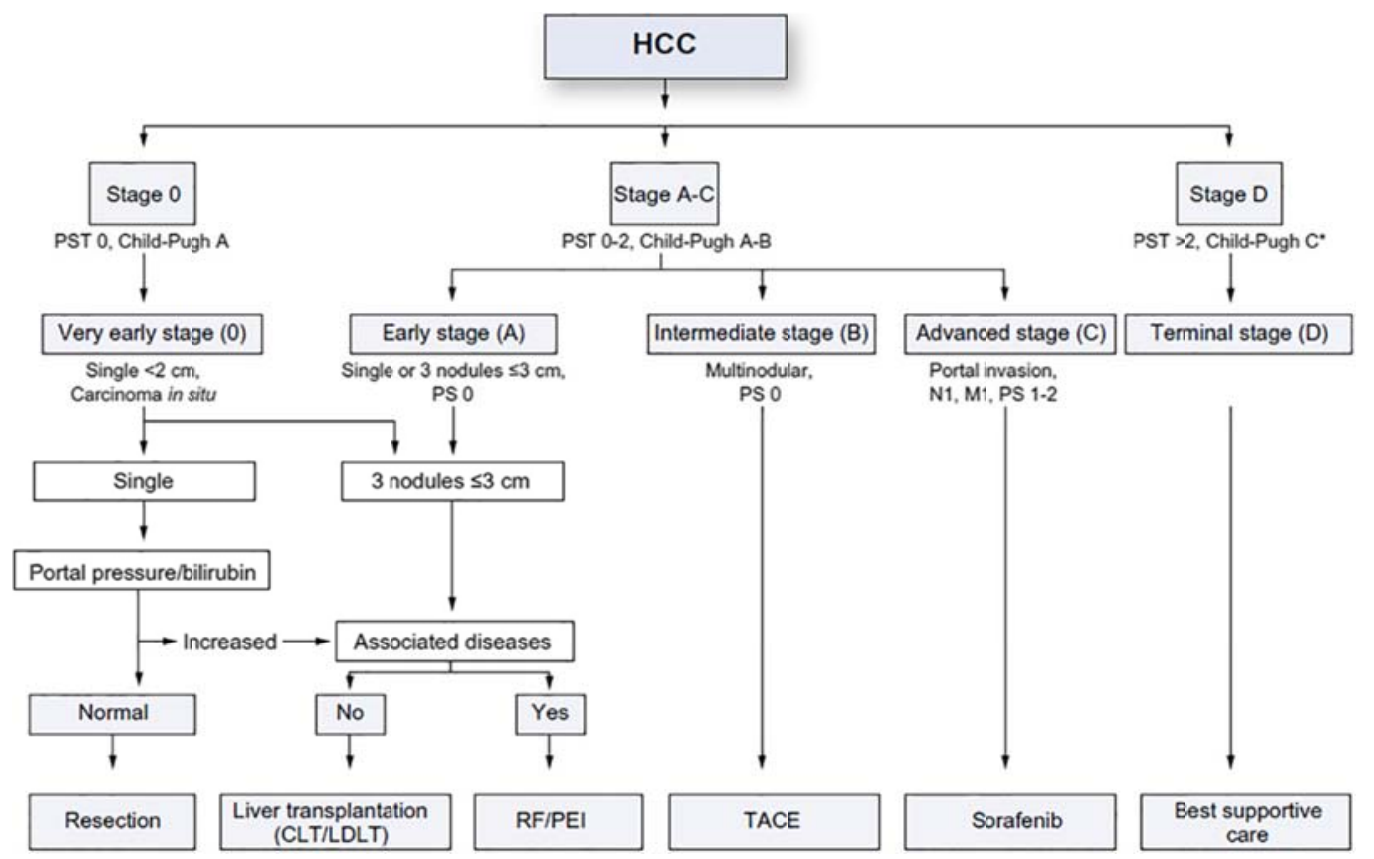

Figure 1. BCLC Staging System, reproduced with permission

The aim of this paper is to review the therapeutic options for HCC for each stage of the BCLC system, illustrating standard treatment strategies and highlighting current issues, using real-patients' clinical-cases based approach. 


\section{Clinical scenarios and therapeutic strategies}

\subsection{Case 1}

A 47-year-old male patient with established cirrhosis due to chronic hepatitis $\mathrm{C}$ infection, non-responder to 2 treatments with pegylated-interferon plus ribavirin, presented in January 2011 with hepatic nodular lesions in his biannual ultrasound HCC screening. His past medical history was remarkable for pulmonary tuberculosis at 21 -year-old and illicit intravenous drug addiction for a decade; he was a current smoker.

Computed tomography showed a $2 \mathrm{~cm}$ hypervascular solitary lesion in segment VII adjacent to the transition of segment V/VIII and to inferior vena cava, enhanced in the arterial phase and washed out in the venous and late phases.

The patient was in good health, and his Eastern Cooperative Oncology Group (ECOG) performance status was 0. Laboratory data demonstrated normal liver function. His Child-Pugh score was A5 and the tumor stage was BCLC stage A; he had no other medical associated conditions.

According to the clinical practice guidelines for HCC, liver transplant was successfully performed in March 2012. Other possible treatment strategies for this stage, as percutaneous ablation or surgical resection were not feasible in this patient due to tumor location and vessels proximity.

\subsubsection{Surgical curative strategies}

Potential curative treatments for HCC are liver transplantation, complete surgical resection and percutaneous ablation, but such treatments are feasible in only $20 \%$ to $25 \%$ of patients, mainly owing to early dissemination ${ }^{[17]}$ or delayed diagnosis due to non-optimized screening protocols.

Recent data have shown favorable 5-year survival rates after resection and liver transplantation (60\%-90\%) and of 70\% after local ablation ${ }^{[1,18,19]}$. Therefore, surgical strategies achieve the best outcomes, being the mainstay of HCC treatment in an intention-to-treat perspective ${ }^{[1]}$.

\section{Liver transplantation}

Liver transplantation is the best option for patients with decompensated cirrhosis, because it allows not only the removal of the primary tumor but also treatment of liver insufficiency ${ }^{[2]}$. The main obstacles are the organ scarcity and the long waiting time for transplantation.

This approach is recommended for patients with tumors within the Milan criteria (a single lesion $\leq 5 \mathrm{~cm}$, or up to three lesions $\leq 3 \mathrm{~cm}$ each) ${ }^{[20]}$. An expansion of the Milan criteria to up-to-seven criteria (as seven being the sum of the size of the largest tumor and the number of tumors in patients without microvascular invasion) was proposed by the Milan Group ${ }^{[20]}$ but requires larger prospective validation studies. Also, The University of California proposed the San Francisco criteria (single lesion of $\leq 6.5 \mathrm{~cm}$, or $2-3$ lesions of $\leq 4.5 \mathrm{~cm}$ with a total tumor diameter $\leq 8 \mathrm{~cm}$ ) and undergone prospective evaluation based on preoperative imaging ${ }^{[21]}$. The limitations of imaging studies, exemplified by tumor under-staging in up to $25 \%$ of patients, have been a major concern for liberalizing new criteria for liver transplantation. So for now, the Milan criteria are the international recommended ones to guide treatment allocation.

\section{Hepatic resection}

Resection is the first line treatment for very early and early BCLC stages HCC in non-cirrhotic patients (corresponding to $5 \%$ of patients in the Western countries and $40 \%$ in Asia) ${ }^{[23,24]}$ because it allows maintenance of appropriate function with the remnant liver volume, reducing life-threatening complications and ensuring a reasonable prognosis ${ }^{[1]}$. 
In the presence of stablished cirrhosis, however, surgical candidates have to be carefully selected to diminish the risk of postoperative liver failure and increased risk of death. The minimal critical remnant liver volume for safe resection is approximately $25 \%(15 \%-40 \%)$ for patients without cirrhosis and $50 \%(25 \%-90 \%)$ for patients with cirrhotic livers ${ }^{[24]}$. If the estimated remnant liver volume is less than the minimal required, preoperative portal vein embolization with the intent to divert portal flow to the non-affected lobe could be tried to lead to compensatory hypertrophy of the non-embolized liver ${ }^{[25]}$. Nevertheless, its effectiveness in cases with an underlying cirrhotic liver have not been sufficiently tested in large controlled studies ${ }^{[1]}$.

Portal hypertension in cirrhotic patients is a relative contraindication for surgical resection, and a hepatic venous pressure gradient $>10 \mathrm{mmHg}$ is the best predictor of postoperative liver decompensation and poor long-term outcome in early stage patients undergoing resection ${ }^{[1,26]}$. The presence of splenomegaly (major diameter $>12 \mathrm{~cm}$ ) or esophageal varices with a platelet count of $<100,000 / \mathrm{mm}^{3}$ correlate with the same endpoints and are easier to identify ${ }^{[27]}$.

Resection techniques have been refined, from the use of new radiofrequency ablation resection devices to laparoscopic approaches, both showing to diminished blood loss ${ }^{[1,2]}$. A recent meta-analysis showed that laparoscopic approach decreases blood loss, transfusion requirement, postoperative morbidity, recovery time, and hospital stay compared to open-surgery, but with no difference in recurrence or survival ${ }^{[28]}$. However, no RCTs were reported in this meta-analysis.

\subsubsection{Case 1 - evolution}

The pathological examination confirmed a moderate differentiated HCC, $1.8 \mathrm{~cm}$ in diameter but with evidence of vascular invasion - corresponding to a stage II (pT2N0M0) of pathological American Joint Committee of Cancer (AJCC) staging system.

In May 2012, fourteen months after liver transplant, under immunosuppressive therapy with tacrolimus, he showed histological evidence of early severe recurrence of viral hepatitis and was started on a pegylated-interferon plus ribavirin regimen. Two months later, he presented with a pathological right femur fracture due to bone metastasis from HCC and functional decline due to refractory bone pain even under optimized surgical and medical care, rapidly transitioning from stage A to D of the BCLC system. Symptomatic care was implemented. He died after 6 months of disease recurrence.

Why such a small tumor recurred after the best standard of care of surgical curative strategies - The problematic of recurrence and the role of microvascular invasion in small tumors.

There is evidence supporting that despite careful selection of patients, early and late HCC recurrences remain a clinical meaningful problem after transplantation (up to $26.7 \%$ patients between 4 and 58 months) ${ }^{[29]}$. Established predictors for HCC recurrence after transplantation are tumor-specific factors (tumor size, number of malignant nodules, presence of microsatellites and vascular invasion) as well as $\alpha$-fetoprotein levels before transplantation ${ }^{[29,30]}$ (that were normal in this case) and immunosuppression levels ${ }^{[31,32]}$. A meta-analysis on pre-transplant risk factors for HCC recurrence showed significant correlation for tumor stage outside the Milan criteria and histologically moderate or poorly differentiated

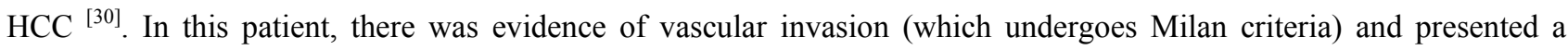
moderate differentiated tumor, and both could explain the bad outcome of the patient.

Overall, treatment options that are currently available for advanced HCC are also potentially feasible after liver transplantation. Nevertheless, specific conditions have to be taken into consideration: influence of immunosuppression, anatomic characteristics of vascular anastomoses, risk of stenosis of the hepatic artery by transarterial techniques, and potential pharmacological interactions between antineoplastic and immunosuppressive drugs and hepatotoxicity of systemic treatments like the multikinase inhibitor sorafenib ${ }^{[33]}$.

After resection, tumor recurrence rate exceeds $70 \%$ at 5 years ${ }^{[34,35]}$ including recurrence due to dissemination and de novo tumors ${ }^{[36]}$. The most powerful predictors of recurrence here are also the presence of microvascular invasion and satellite 
tumor lesions ${ }^{[34-36]}$. This suggests that the majority of recurrences are due to dissemination from the primary tumor and not metachronous tumors developing in a liver with cirrhosis ${ }^{[37]}$.

There is no effective adjuvant therapy that can reduce recurrence rates ${ }^{[38]}$.

\subsubsection{Palliative care in advanced disease}

Patients with terminal HCC are those presenting with tumors leading to a very poor ECOG (3-4) or Child-Pugh C patients with tumors beyond the transplantation threshold - corresponding to patients like the one presented above, with BCLC-D, with a median survival being less than 3-4 months. The most frequent symptoms are anorexia, fatigue, ascites, nausea or vomiting, pruritus and constipation.

The general symptomatic approach is similar to that for any terminal patient, irrespective of the underlying disease. However, there are some specificities that clinicians should take into account due to hepatic dysfunction, to minimize iatrogenic suffering. Nutritional status assessment is important for identifying the risk of deteriorating quality of life or functional status, although routine artificial nutrition is not justified. Non-steroid anti-inflammatory drugs should be avoided for pain management due to increased risk of variceal hemorrhage, impaired renal function, and development of refractory ascites and, aiming for visceral pain control, opioids are the first-line choice; radiotherapy has a place for refractory pain due to metastasis to lymph nodes, bone, brain, or other sites ${ }^{[39]}$.

\subsection{Case 2}

A 47-year-old male patient with established cirrhosis due to alcoholic hepatitis (abstinent since 2004), complicated with portal hypertension (esophageal varices, thrombocytopenia due to hypersplenism), presented in December 2011 with a nodular lesion in the liver in his biannual ultrasound HCC screening. His past medical history was remarkable for active smoking and chronic obstructive pulmonary disease GOLD 3, osteopenia of the femur, dysarthria due to an infectious meningitis and asymptomatic gallstones.
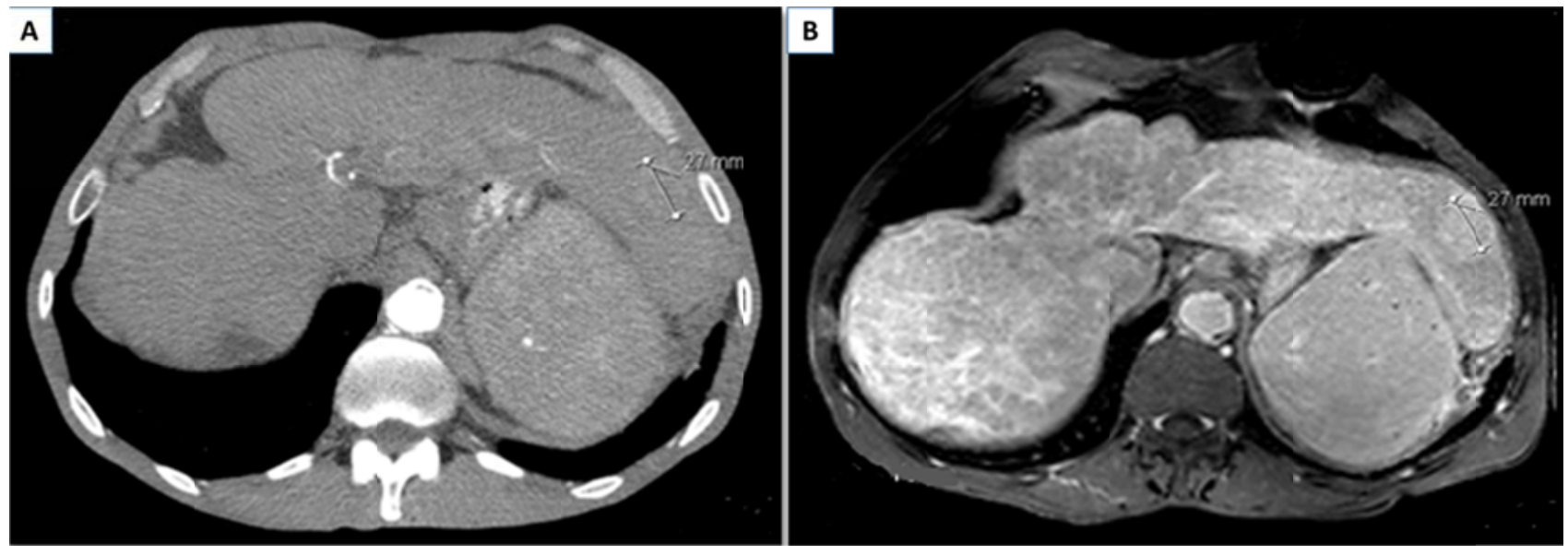

Figure 2. Hypervascular solitary lesion with $2.7 \mathrm{~cm}$ in segment II, compatible with HCC. A. Abdominal tomography. B. Abdominal magnetic resonance imaging

Computed tomography showed a $2.7 \mathrm{~cm}$ hypervascular solitary lesion in the left lobe (segment II), enhanced in the arterial phase and washed out in the late and venous phases (see Figure 2A) and it showed the same vascular enhancing characteristics on magnetic resonance imaging, with T2-hypersignal (see Figure 2B). The histopathological examination confirmed a fibrolamellar HCC. 
The patient was in good health, and his ECOG performance status was 0. Laboratory data demonstrated normal liver function. His Child-Pugh score was A5 and the tumor stage was BCLC stage A.

According to the clinical practice guidelines for HCC, he was a candidate for curative treatment. Due to his associated medical condition - chronic lung disease, he was not suitable for surgical approaches and he was subjected to radiofrequency ablation in January 2012, with no evidence of tumor in the first follow-up tomography (1 month after) (see Figure 3) and preserved liver function.

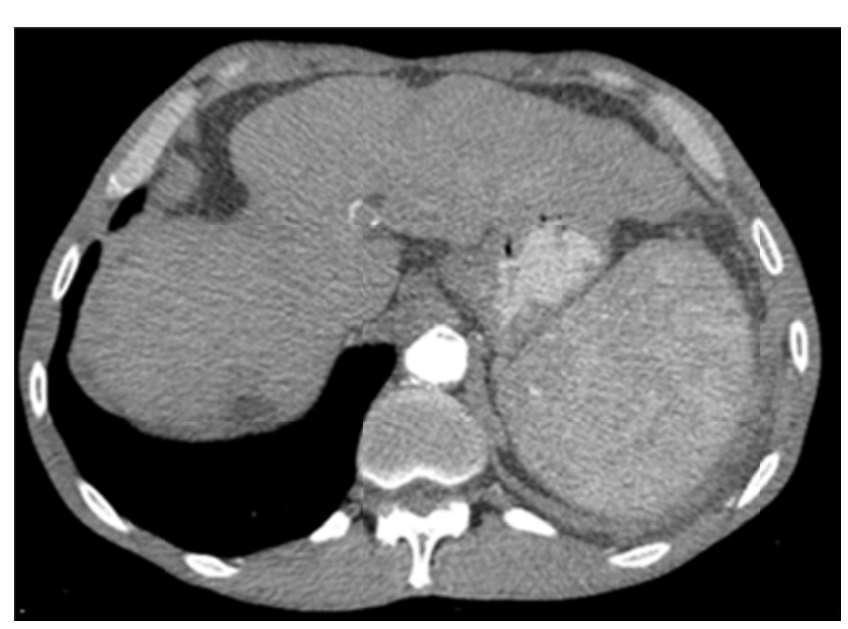

Figure 3. Tomography imaging 1 month after radiofrequency ablation, showing no evidence of tumor

sparing ${ }^{[40,41]}$. These assumptions are based on trials that showed excellent similar survival outcomes of early stage tumors with either resection or RFA $-60 \%-70 \%$ at 5 years ${ }^{[18,27]}$. There are no robust data comparing ablation with liver transplantation, with the available case-control studies supporting RFA as a non-inferior ${ }^{[42]}$ and more cost-effective ${ }^{[43]}$ treatment for very early HCC.

\section{Radiofrequency ablation}

Of the available options, RFA is clearly the standard of care for this stage 0-A HCC patients with stable liver function ${ }^{[1,9,44]}$. For RFA feasibility, the tumor shall be clearly seen with the ultrasound. The hyperthermic coagulative necrosis generated by RFA induces a safety ring in the surrounding tissue, which might eliminate small-undetected satellite lesions, and mitigate "free margins". With the latest improvements of the technique, it is possible to induce a wide region of tumor necrosis of $4 \mathrm{~cm}$. So, it is then understandable that survival of patients with $\mathrm{HCC}<3 \mathrm{~cm}$ treated by ablation competes with that of surgical candidates. In $\mathrm{HCC}>3 \mathrm{~cm}$, the failure rate of RFA increases and the same applies to multifocal HCC even if tumor size is less than $3 \mathrm{~cm}^{[45,46]}$. In such instance, resection or the association of chemoembolization and ablation has been suggested to improve survival ${ }^{[44,47]}$, but there is lack of evidence due to paucity of optimal patient selection in trials.

All treatment strategies have inherent complications that clinicians cannot neglect. Some authors reported higher complication rates with RFA versus PEI (like pleural effusion and peritoneal hemorrhage), although with no statistically significance, but those possibilities when choosing eligible patients should be considered, being commonly related to tumor location ${ }^{[48-50]}$. Also, there is an actual probability of incomplete histopathological response after RFA, as this technique is size-dependent, some limitations exists in relation to tumor vascularization [presence of large ( $>3 \mathrm{~mm})$ confined vessels results in a drop of the rate of complete necrosis to $<50 \%{ }^{[51]}$ due to a cooling-related effect] and limitations due to problematic tumor location (subcapsular or within $5 \mathrm{~mm}$ from the liver hila or common bile duct ${ }^{[52,53]}$ ) Published by Sciedu Press 
- accounting for $10 \%-15 \%$ of tumors ${ }^{[1]}$. In these scenarios, there is an increased risk of incomplete eradication and local tumor progression. It is also, therefore, essential to undertake appropriate follow-up for these patients, with first tomography 1 month after the procedure, like illustrated in the clinical case.

In RFA, survival rates have been reported to be $39.9 \%-68.5 \%$ at 5 years and local tumor progression rates to be $2.4 \%-16.9 \%{ }^{[18,54]}$. Mortality and morbidity rates of RFA have been reported ${ }^{[18,55,56]}$ to be $0.9 \%-7.9 \%$ and $0-1.5 \%$, respectively.

There are contradictory data, from the 2 RCTs available ${ }^{[41,57]}$, regarding the use of RFA as first-line treatment for small HCC. For tumors with a high risk of recurrence, RFA may not be considered as a primary treatment strategy. The pathological information obtained at resection, such as satellite formation and microvascular invasion, may allow enlisting for rescue transplantation because of risk of recurrence and this is not feasible with RFA.

\section{Other percutaneous ablation techniques}

Since the advent of RFA in the 1990s, the former ablations techniques became second-line choice for these small tumors.

\section{Percutaneous ethanol injection}

Multiple randomized control trials (RCTs) consistently showed evidence of superiority of RFA to PEI in terms of number of treatment sessions needed, treatment response and recurrence rates ${ }^{[48-50,58-60]}$. However, the assessment of the impact of RFA on survival in those RCTs has been more controversial, despite the trend favoring RFA ${ }^{[58,60]}$.

PEI still has a role in achieving complete response when the residual viable tissue is minimal or as an alternative when the tumor location implies high risk of adverse events with RFA, as discussed above. This therapeutic option is more commonly used in oriental countries. PEI achieves complete tumor necrosis in $90 \%$ of tumors $<2 \mathrm{~cm}, 70 \%$ in those of $2 \mathrm{~cm}-3 \mathrm{~cm}$ and $50 \%$ in those between $3 \mathrm{~cm}$ and $5 \mathrm{~cm}{ }^{[44,61,62]}$. The fact that its action may be blocked either by the intra-tumoral fibrotic septa or the tumor capsule, undermines the curative capacity of this technique, particularly in tumors larger than $2 \mathrm{~cm}^{[1]}$. In patients with Child-Pugh A cirrhosis and early-stage tumors, treatment with PEI has been shown to result in 5-year survival rates of $47 \%-53 \%{ }^{[61,63]}$. The major limitation of PEI is the high local recurrence rate, which may reach $43 \%$ in lesions exceeding $3 \mathrm{~cm}^{[64]}$.

\section{Microwave coagulation}

One RCT demonstrated that the number of treatment sessions was fewer with RFA than with MWC, although the rates of complete therapeutic effect, major complications, and local tumor progression were not statistically different between the two therapies ${ }^{[49]}$. The main advantage of MWC compared to RFA is that treatment efficacy is less affected by vessels located in the proximity of the tumor. Therefore, it may be an option in tumors with high-risk location for RFA.

\section{Cryoablation}

Cryoablation had limited application in HCC, and no RCT have been reported ${ }^{[65]}$. The complication rate is not negligible, particularly because of the risk for "cryoshock", a life threatening condition resulting in multi-organ failure, severe coagulopathy and disseminated intravascular coagulation following cryoablation ${ }^{[1]}$.

\section{Laser ablation}

LA represents one of currently available loco-ablative techniques. Multiple cohort studies recently published show promising results but there was only one RCT study comparing LA with RFA approaches in 81 cirrhotic patients' biopsy proven $\leq 4 \mathrm{~cm}$ HCC. They reported no significant difference overall in survival rates between the two methods, at 1, 3 and 
5 years. However, they demonstrated a statistically significant higher survival rate for RFA over LA for Child A patients with small nodules $(\leq 2.5 \mathrm{~cm})^{[66]}$.

\section{Evaluation of treatment response}

To evaluate de treatment response in HCC when loco-regional techniques are used, one should always consider the extent of tumor necrosis. A recent modification of the response evaluation criteria in solid tumors (modified RECIST) ${ }^{[67]}$ takes this into account, estimating the degree of necrosis by dynamic computed tomography or magnetic resonance imaging. It is now the standard approach recommended by the international associations.

\subsubsection{Case 2 - evolution}

The patient remained stable in terms of his hepatic chronic disease and showed no evidence of recurrence in the next 44 months. In August 2014, there were multiple diffuse hepatic nodules in ultrasound screening. Tomography showed multiple hypervascular nodules with HCC characteristics in segment V $(1.7 \mathrm{~cm}$ and $1.8 \mathrm{~cm})$, segment VI $(5.1 \mathrm{~cm})$, and segment VII $(1.7 \mathrm{~cm}$ and $1.9 \mathrm{~cm})$ and multiple subcapsular ones. Therefore, he recurred with multifocal HCC, transitioning from stage A to $\mathrm{C}$ of the BCLC system.

He was started on sorafenib in September 2014, initially with $800 \mathrm{mg}$. Currently, he is clinically stable with no adverse effects under 400mg-day sorafenib, ECOG 0 , no evidence of decompensation of the underlying liver disease or metastatic extra-hepatic disease.

\subsection{Case 3}

A 63-year-old male patient with established cirrhosis due to hereditary hemochromatosis, complicated with portal hypertension (esophageal varices with previous hypertensive bleeding episodes, pancytopenia due to hypersplenism and refractory moderate ascites), presented in April 2014 with a hepatic nodular lesion in his biannual ultrasound HCC screening. His past medical history was remarkable for partial gastrectomy in 2007 due to early gastric cancer without evidence of recurrence and type 2 diabetes mellitus. He suffers also from porphyria cutanea tarda secondary to is primary iron-overload syndrome.

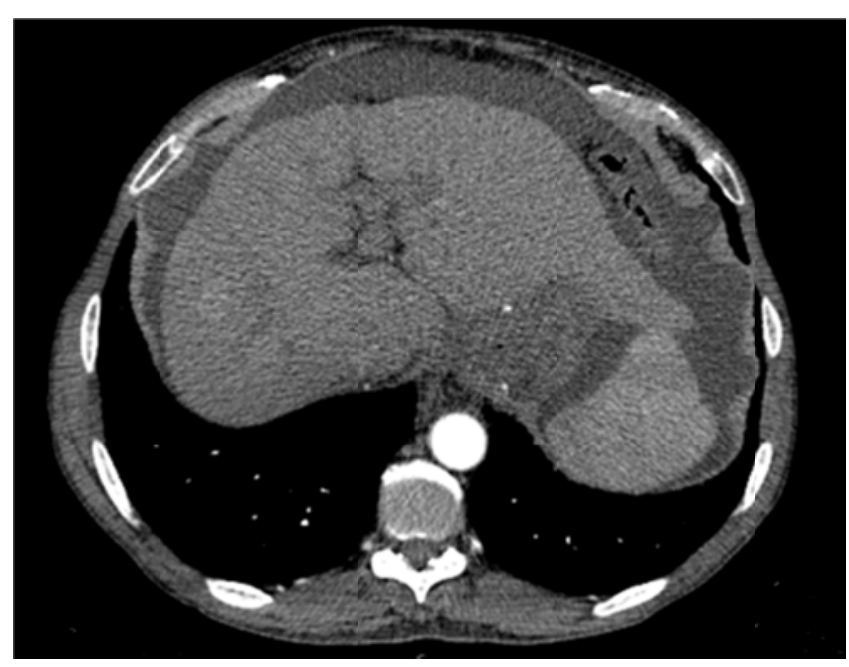

Figure 4. Abdominal tomography showing the $2.3 \mathrm{~cm}$ hypervascular solitary lesion in segment VII/VIII, compatible with HCC.
Computed tomography (CT) showed a $2.3 \mathrm{~cm}$ hypervascular solitary lesion in segment VII/VIII, enhanced in the arterial phase and washed out in the late and venous phases (see Figure 4).

The patient was in good health, and his ECOG performance status was 0 . Laboratory data demonstrated normal liver function. His Child-Pugh score was A6 and the tumor stage was BCLC stage B.

According to the clinical practice guidelines for HCC, due to concomitant mild to moderate ascites refractory to medical treatment, he was subjected to transarterial chemoembolization with $50 \mathrm{mg}$ doxorubicin on May 2015, with completely destruction of tumor blood supply (see Figure 5). Starting follow-up, he will be submitted to abdominal tomography in a month 

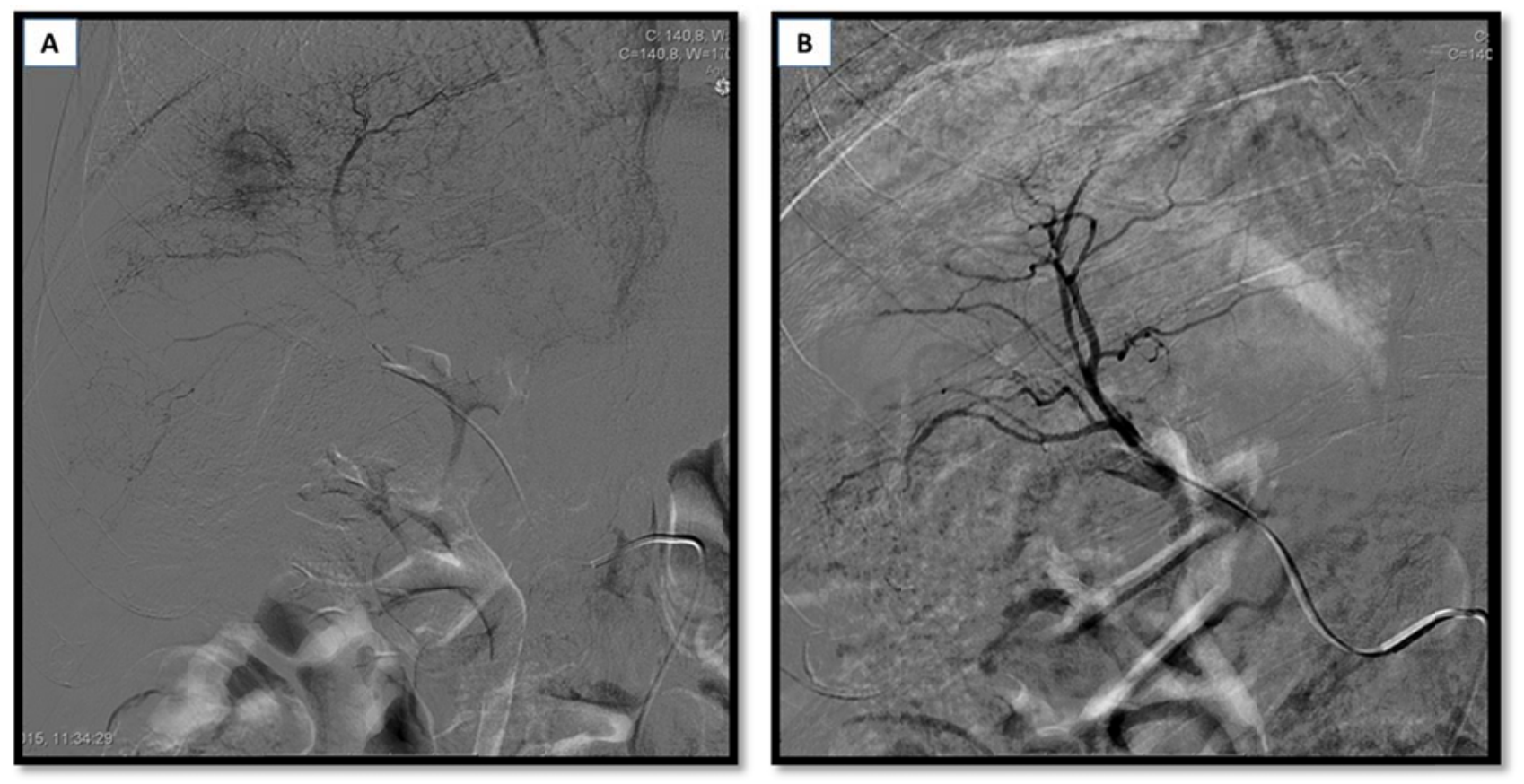

Figure 5. Transarterial chemoembolization of the nodule. A. Pre-procedure imaging. B. Immediate post-procedure imaging showing completely destruction of tumor blood supply

\subsubsection{Loco-regional palliative strategies}

The dominant arterial vascular supply ( $90 \%$ from the hepatic artery vs. $10 \%$ from portal vein) of HCC provides the rationale to treat them through selective delivery of anticancer agents and/or blocking to blood supply, inducing tumor necrosis. The transarterial therapies available include transarterial bland embolization, chemotherapy, chemoembolization and radioembolization.

\section{Transarterial chemoembolization}

Among non-curative therapies, cumulative meta-analysis have positioned TACE as the current standard of care for patients in BCLC-B stage ${ }^{[68]}$, as it has shown to positively impact survival ${ }^{[69]}$.

TACE combines selective arterial obstruction with chemotherapy injection. Tolerance to the procedure has improved by the use of drug-eluting beads (DEB-TACE) that obstruct arterial vessels and slowly release chemo therapy in a controlled mode over a 1-week period, enhancing exposure of tumor cells to the agent and simultaneously reducing systemic toxicity, responsible for haematological adverse events ${ }^{[70]}$. It was associated with a non-significant trend of better antitumoral effect $^{[71]}$.

In centers where it is possible to conduct TACE technique properly and with an adequate policy to stop TACE at the time of liver failure or lack of treatment response, this treatment can lead to a favorable median survival of more than 4 years ${ }^{[72,73]}$.

BCLC-B stage includes a wide range of tumor burden and liver function impairment (Child-Pugh scores from 5 to 9). Also, in several studies patients with total bilirubin $>3 \mathrm{mg} / \mathrm{dl}$ were excluded to TACE's procedure ${ }^{[74,75]}$. Because of this broad spectrum of possible presentations, Bolondi et al. ${ }^{[76]}$ proposed a substaging of BCLC-B patients from B1 to B4, taking into account the tumor burden and Child-Pugh score (A5 to B9). This way to stratify patients revealed decreased survival for higher B substages, suggesting that TACE should only be performed for early substaging groups. 
There is no consensus on a definition for TACE, nor for when to consider the referral of the patient to an alternative treatment. Despite the absence of solid evidence to define TACE refractoriness, current EASL guidelines recommend switching to sorafenib if BCLC-C patients are non-responsive to at least two cycles of TACE, meaning downward treatment stage migration, if they demonstrate disease progression or poor tolerance after first or second TACE ${ }^{[67,77]}$.

\section{Transarterial radioembolization}

Transarterial radioembolization (TARE) is a different technique: it does not base its effect in arterial obstruction but rather in the local action of $\beta$-radiation through the lodging of yttrium-loaded glass or resin spheres in the vessels that feed the tumor ${ }^{[78]}$. The procedure is well tolerated, and cohort studies with heterogeneous populations suggest it may provide survival rates similar to TACE and sorafenib, particularly in the setting of portal vein thrombosis (a contra-indication to TACE, corresponding to a migration to stage $\mathrm{C}$ of the BCLC staging system) ${ }^{[68]}$. Ongoing RCTs in first-line combined or in monotherapy versus sorafenib or as a second-line choice versus placebo will define the population that benefits from this approach.

\subsubsection{Evaluation of treatment response}

Like for the curative loco-regional techniques discussed in case 2, the modified RECIST criteria for evaluation of tumor response shall be used.

\subsection{Case 4}

A 59-year-old female patient with alcoholic cirrhosis, complicated with portal hypertension (esophageal varices, thrombocytopenia due to hypersplenism) was referred to our Hepatology Unit outpatient clinic for evaluation of liver transplant suitability in 2010. On the initial ultrasound study, she presented multiple hepatic nodular lesions. Her past medical history was remarkable for positive hepatitis B core antibody, controlled asthma, chronic gastritis (negative for H. pylori) and paroxistic atrial fibrillation. CT showed 3 nodular lesions in the right lobe, with 1,2 and $4 \mathrm{~cm}$, enhanced in the arterial phase and with portal wash out.

The patient was in good health, and her ECOG performance status was 0. Laboratory data demonstrated normal liver function. Her Child-Pugh score was A5, and the tumor stage was BCLC stage B.

According to the clinical practice guidelines for HCC, because the multifocal HCC dimensions were beyond Milan criteria, downstaging TACE was considered. After 3 sessions of TACE with doxorubicin during 2010, there was evidence of tumor progression, transitioning to stage $\mathrm{C}$ of the BCLC system.

She was started on sorafenib in December 2010, with some erratic compliance for the first 5 months. She showed clinical and radiological stability for almost 2 years. In January 2013 she developed physical impairment, with ECOG performance status 1-2, progression to Child-Pugh B8 with refractory ascites and hepatorenal syndrome, without evidence of tumor mass progression. She died in August 2013.

\section{Systemic palliative treatment}

At diagnosis, approximately $70 \%$ of the patients with HCC are not eligible for curative surgery ${ }^{[79,80]}$. HCC is recognized as one of the most chemo-resistant tumor types, with an overall response rate to systemic chemotherapy lower than $10 \%{ }^{[81]}$. Until 2007 no systemic drug was recommended for patients in advanced stages, a remarkable situation in oncology.

\subsubsection{Molecular targeted therapies}

Sorafenib, an oral multikinase inhibitor with antiproliferative and antiangiogenic properties, is the only systemic treatment demonstrating a statistically significant but modest overall survival benefit (31\% decrease in the relative risk of death) and significant impact on disease progression ${ }^{[69,82]}$, being widely accepted as a standard first-line systemic therapy. 
There are no clinical, molecular biomarkers or functional imaging techniques available to identify the best responders to sorafenib, to predict who responds best or to identify when efficacy is lost.

It is consensually recommended for patients with advanced tumors (BCLC stage C - extra-hepatic lesions, macrovascular invasion) or those who do not response to loco-regional therapies, provided that they still have well-preserved liver function (Child-Pugh A class) ${ }^{[1,7,9,83]}$. No clear recommendation can be made to Child-Pugh B patients, although some cohort studies reported a similar safety profile in such patients with no liver function decompensation ${ }^{[84,85]}$. It is recommended to maintain sorafenib at least until progression, and beyond that point second-line studies can be considered.

Sorafenib is a well-tolerated drug; the most common adverse events observed in these studies included diarrhea, fatigue, weight loss and palmar-plantar erythrodysesthesia syndrome. Drug-related adverse events were considered manageable, and no death related with toxicity was described ${ }^{[53,61]}$.

\section{Combination of sorafenib with other curative or palliative treatments}

The role of sorafenib in early stages of the disease is yet to be defined. The possibility of using a systemic agent after an intended curative therapy such as hepatic resection or complete local ablation could impact the high recurrence rates, by undermining micro-metastatic disease that may be present at the time of resection and inhibiting subsequent tumor angiogenesis. In practice, the few published studies did not prove that adjuvant therapies decrease post-resection HCC recurrence ${ }^{[86]}$.

Sorafenib used in patients on the waiting list for liver transplantation who are anticipated to wait less than 6 months, was proved to be cost-effective compared with no therapy at all. As waiting times increased beyond 6 months, the use of sorafenib became less effective ${ }^{[87]}$. However, in terms of safety in the pre-transplant setting, the available studies reported significant increased risk of biliary complications and acute cellular rejection ${ }^{[88,89]}$. Therefore, under current evidence, the use of sorafenib for stabilization or downstaging of HCC in pre-transplant setting, cannot be formally recommended by scientific groups.

In intermediate stages, three RCT investigated the outcomes in patients who received sorafenib in conjunction with TACE $^{[90-93]}$. Sorafenib was tested after completion of TACE (sequential), before TACE, held at time of TACE (interrupted) or in a continuous fashion. These studies showed controversial results, with no clear clinically meaningful increase in survival. There are 2 more RCT ongoing further exploring the role of TACE with or without sorafenib (ECOG 1208 in United States and NCI01324076 in the United Kingdom).

\section{Other systemic treatments}

Several systemic therapies, including chemotherapy, hormonal compounds, immunotherapy showed inconclusive or negative results, with marginal survival benefit in most clinical trials ${ }^{[17]}$ but this result can partly be due to poor efficacy and increased toxicity due to underlying cirrhosis ${ }^{[94]}$.

\subsubsection{Chemotherapy}

In recent years, there have been multiple studies of chemotherapy regimens for HCC, most of them based on doxorubicin ${ }^{[68]}$. The gemcitabine plus oxaliplatin (GEMOX) regimen appeared to be the most promising, based on its lack of renal and hepatic toxicity in patients with underlying cirrhosis and its interesting efficacy in phase II trials ${ }^{[95-97]}$. The largest multicenter study suggested that GEMOX is effective with an acceptable profile of safety; the induced tumor response allowed a secondary local therapy option that was not initially feasible in a significant proportion of patients, which suggests that it could be indicated as a first line treatment for patients who may particularly benefit from tumor downsizing ${ }^{[2]}$. GEMOX may be a therapeutic option after sorafenib discontinuation in the absence of a validated second line treatment. 
No regimen has been proven effective in prolonging the survival of patients with $\mathrm{HCC}{ }^{[98-100]}$. Therefore, the use of systemic chemotherapy in HCC is still discouraged by all scientific associations ${ }^{[1,7-9,11]}$.

\subsubsection{Combination of sorafenib with other systemic agents}

Sorafenib has also been evaluated in combination with other systemic chemotherapeutic agents with a goal to improve efficacy: doxorubicin ${ }^{[101]}$, octreotide ${ }^{[102]}$ and oxaliplatin ${ }^{[103]}$, tegafur/uracil ${ }^{[104]}$, cisplatin and gemcitabine ${ }^{[105]}$. All of these studies reported some survival advantage over monotherapy with sorafenib, but they have small sample sizes. Large randomized double-blind studies are needed to establish the role and toxicity profile of these combination regimens.

\section{Conclusions}

Major changes had occurred in the diagnosis and management of HCC. From a global perspective the most emergent need is to improve HCC prevention, namely, avoiding fibrosis progression, acting directly on the cause that promotes the liver disease (treating hepatitis B, hepatitis $\mathrm{C}$, promoting abstinence, etc.). Because most $\mathrm{HCC}$ are still diagnosed at late stages, where treatment options are palliative, it is also crucial to foment awareness in order to promote timely surveillance of at-risk patients. Not a single therapeutic strategy fits all HCC presentations, as patient and their disease-specific features, due to underlying chronic hepatic disease, are also crucial for decision making.

For outcome prediction, treatment planning and research, the BCLC staging system is the current recommendation. One of the greatest problems limiting potential curative treatment for HCC is the high risk of recurrence after curative strategies and the lack of effective approaches to reduce it. Also, no standard of care currently exists for second-line treatment in HCC's advanced stages. Systemic agents other than sorafenib are not currently recommended for management of HCC, existing an actual effort to search for other non-hepatotoxic systemic regimens.

Several areas in management of HCC are under investigation, including the use of biomarkers to identify treatment responders, use of neoadjuvant and/or adjuvant therapies to decrease recurrence after resection or ablation, combinations of local and systemic therapies, combinations of systemic targeted therapies, and second-line therapies.

Overall, HCC is a "dynamic" disease along its course, conducting to different therapeutic approaches, which depend on the initial stage, its evolution and treatment response, making feasible that, for the same patient, different therapeutic strategies may be used along the time.

\section{References}

[1] European Association for the Study of the L, European Organisation for R, Treatment Of C. EASL-EORTC clinical practice guidelines: management of hepatocellular carcinoma. Journal of Hepatology. 2012; 56(4): 908-43. PMid: 22424438. http://dx.doi.org/10.1016/j.jhep.2011.12.001

[2] Zaanan A, Williet N, Hebbar M, et al. Gemcitabine plus oxaliplatin in advanced hepatocellular carcinoma: a large multicenter AGEO study. Journal of Hepatology. 2013; 58(1): 81-8. PMid: 22989572. http://dx.doi.org/10.1016/j.jhep.2012.09.006

[3] Ferlay J, Soerjomataram I, Dikshit R, et al. Cancer incidence and mortality worldwide: sources, methods and major patterns in GLOBOCAN 2012. International journal of cancer Journal international du cancer. 2015; 136(5): E359-86. PMid: 25220842. http://dx.doi.org/10.1002/ijc. 29210

[4] Kim WR, Gores GJ, Benson JT, et al. Mortality and hospital utilization for hepatocellular carcinoma in the United States. Gastroenterology. 2005; 129(2): 486-93. PMid: 16083705. http://dx.doi.org/10.1016/j.gastro.2005.05.001

[5] Cucchetti A, Piscaglia F, Caturelli E, et al. Comparison of recurrence of hepatocellular carcinoma after resection in patients with cirrhosis to its occurrence in a surveilled cirrhotic population. Annals of surgical oncology. 2009; 16(2): 413-22. PMid: 19034578. http://dx.doi.org/10.1245/s10434-008-0232-4

[6] Poon RT, Fan ST, Ng IO, et al. Different risk factors and prognosis for early and late intrahepatic recurrence after resection of hepatocellular carcinoma. Cancer. 2000; 89(3): 500-7. PMid: 10931448. 
[7] Bruix J, Sherman M. American Association for the Study of Liver D. Management of hepatocellular carcinoma: an update. Hepatology. 2011; 53(3): 1020-2. PMid: 21374666. http://dx.doi.org/10.1002/hep.24199

[8] Benson AB, Abrams TA, Ben-Josef E, et al. NCCN clinical practice guidelines in oncology: hepatobiliary cancers. Journal of the National Comprehensive Cancer Network: JNCCN. 2009; 7(4): 350-91. PMid: 19406039.

[9] Omata M, Lesmana LA, Tateishi R, et al. Asian Pacific Association for the Study of the Liver consensus recommendations on hepatocellular carcinoma. Hepatology international. 2010; 4(2): 439-74. PMid: 20827404. http://dx.doi.org/10.1007/s12072-010-9165-7

[10] Ferenci P, Fried M, Labrecque D, et al. World Gastroenterology Organisation Guideline. Hepatocellular carcinoma (HCC): a global perspective. Journal of gastrointestinal and liver diseases: JGLD. 2010; 19(3): 311-7. PMid: 20922197.

[11] Italian Association for the Study of the L, Panel AE, Committee AC, et al. Position paper of the Italian Association for the Study of the Liver (AISF): the multidisciplinary clinical approach to hepatocellular carcinoma. Digestive and liver disease: official journal of the Italian Society of Gastroenterology and the Italian Association for the Study of the Liver. 2013; 45(9): 712-23. PMid: 23769756. http://dx.doi.org/10.1016/j.dld.2013.01.012

[12] Trinchet JC, Chaffaut C, Bourcier V, et al. Ultrasonographic surveillance of hepatocellular carcinoma in cirrhosis: a randomized trial comparing 3- and 6-month periodicities. Hepatology. 2011; 54(6): 1987-97. PMid: 22144108. http://dx.doi.org/10.1002/hep.24545

[13] Forner A, Llovet JM, Bruix J. Hepatocellular carcinoma. Lancet. 2012; 379(9822): 1245-55. PMid: 22353262. http://dx.doi.org/10.1016/S0140-6736(11)61347-0

[14] Wang CH, Wey KC, Mo LR, et al. Current Trends and Recent Advances in Diagnosis, Therapy, and Prevention of Hepatocellular Carcinoma. Asian Pacific journal of cancer prevention: APJCP. 2015; 16(9): 3595-604. PMid: 25987009.

[15] Flores A, Marrero JA. Emerging trends in hepatocellular carcinoma: focus on diagnosis and therapeutics. Clinical Medicine Insights Oncology. 2014; 8: 71-6. PMid: 24899827. http://dx.doi.org/10.4137/CMO.S9926

[16] Marrero JA. Staging systems for hepatocellular carcinoma: should we all use the BCLC system? Journal of Hepatology. 2006; 44(4): 630-2. PMid: 16503077. http://dx.doi.org/10.1016/j.jhep.2006.02.003

[17] Bruix J, Sherman M, Llovet JM, et al. Clinical management of hepatocellular carcinoma. Conclusions of the Barcelona-2000 EASL conference. European Association for the Study of the Liver. Journal of Hepatology. 2001; 35(3): 421-30. PMid: 11592607.

[18] Livraghi T, Meloni F, Di Stasi M, et al. Sustained complete response and complications rates after radiofrequency ablation of very early hepatocellular carcinoma in cirrhosis: Is resection still the treatment of choice? Hepatology. 2008; 47(1): 82-9. PMid: 18008357. http://dx.doi.org/10.1002/hep.21933

[19] Takayama T, Makuuchi M, Hirohashi S, et al. Early hepatocellular carcinoma as an entity with a high rate of surgical cure. Hepatology. 1998; 28(5): 1241-6. PMid: 9794907. http://dx.doi.org/10.1002/hep.510280511

[20] Mazzaferro V, Llovet JM, Miceli R, et al. Predicting survival after liver transplantation in patients with hepatocellular carcinoma beyond the Milan criteria: a retrospective, exploratory analysis. The Lancet Oncology. 2009; 10(1): 35-43. PMid: 19058754. http://dx.doi.org/10.1016/S1470-2045(08)70284-5

[21] Yao FY. Expanded criteria for liver transplantation in patients with hepatocellular carcinoma. Hepatology research: the official journal of the Japan Society of Hepatology. 2007; 37 Suppl 2: S267-74. PMid: 17877493. http://dx.doi.org/10.1111/j.1872-034X.2007.00195.x

[22] Belghiti J, Hiramatsu K, Benoist S, et al. Seven hundred forty-seven hepatectomies in the 1990s: an update to evaluate the actual risk of liver resection. Journal of the American College of Surgeons. 2000; 191(1): 38-46. PMid: 10898182.

[23] Lang H, Sotiropoulos GC, Domland M, et al. Liver resection for hepatocellular carcinoma in non-cirrhotic liver without underlying viral hepatitis. The British journal of surgery. 2005; 92(2): 198-202. PMid: 15609381.

http://dx.doi.org/10.1002/bjs.4763

[24] Gomaa AI, Waked I. Recent advances in multidisciplinary management of hepatocellular carcinoma. World journal of hepatology. 2015; 7(4): 673-87. PMid: 25866604. http://dx.doi.org/10.4254/wjh.v7.i4.673

[25] Tanaka H, Hirohashi K, Kubo S, et al. Preoperative portal vein embolization improves prognosis after right hepatectomy for hepatocellular carcinoma in patients with impaired hepatic function. The British journal of surgery. 2000; 87(7): 879-82. PMid: 10931022. http://dx.doi.org/10.1046/j.1365-2168.2000.01438.x

[26] Bruix J, Castells A, Bosch J, et al. Surgical resection of hepatocellular carcinoma in cirrhotic patients: prognostic value of preoperative portal pressure. Gastroenterology. 1996; 111(4): 1018-22. PMid: 8831597.

[27] Roayaie S, Obeidat K, Sposito C, et al. Resection of hepatocellular cancer $</=2 \mathrm{~cm}$ : results from two Western centers. Hepatology. 2013; 57(4): 1426-35. PMid: 22576353. http://dx.doi.org/10.1002/hep.25832 
[28] Rao A, Rao G, Ahmed I. Laparoscopic or open liver resection? Let systematic review decide it. American journal of surgery. 2012; 204(2): 222-31. PMid: 22245507. http://dx.doi.org/10.1016/j.amjsurg.2011.08.013

[29] Kornberg A, Kupper B, Tannapfel A, et al. Long-term survival after recurrent hepatocellular carcinoma in liver transplant patients: clinical patterns and outcome variables. European journal of surgical oncology: the journal of the European Society of Surgical Oncology and the British Association of Surgical Oncology. 2010; 36(3): 275-80. PMid: 19857941. http://dx.doi.org/10.1016/j.ejso.2009.10.001

[30] Sotiropoulos GC, Molmenti EP, Losch C, et al. Meta-analysis of tumor recurrence after liver transplantation for hepatocellular carcinoma based on 1,198 cases. European journal of medical research. 2007; 12(10): 527-34. PMid: 18024261.

[31] Chinnakotla S, Davis GL, Vasani S, et al. Impact of sirolimus on the recurrence of hepatocellular carcinoma after liver transplantation. Liver transplantation: official publication of the American Association for the Study of Liver Diseases and the International Liver Transplantation Society. 2009; 15(12): 1834-42. PMid: 19938137. http://dx.doi.org/10.1002/lt.21953

[32] Vivarelli M, Cucchetti A, La Barba G, et al. Liver transplantation for hepatocellular carcinoma under calcineurin inhibitors: reassessment of risk factors for tumor recurrence. Annals of Surgery. 2008; 248(5): 857-62. PMid: 18948815. http://dx.doi.org/10.1097/SLA.0b013e3181896278

[33] Welker MW, Bechstein WO, Zeuzem S, et al. Recurrent hepatocellular carcinoma after liver transplantation - an emerging clinical challenge. Transplant international: official journal of the European Society for Organ Transplantation. 2013; 26(2): 109-18. PMid: 22994652. http://dx.doi.org/10.1111/j.1432-2277.2012.01562.x

[34] Llovet JM, Fuster J, Bruix J. Intention-to-treat analysis of surgical treatment for early hepatocellular carcinoma: resection versus transplantation. Hepatology. 1999; 30(6): 1434-40. PMid: 10573522. http://dx.doi.org/10.1002/hep.510300629

[35] Poon RT, Fan ST, Lo CM, et al. Intrahepatic recurrence after curative resection of hepatocellular carcinoma: long-term results of treatment and prognostic factors. Annals of Surgery. 1999; 229(2): 216-22. PMid: 10024103.

[36] Imamura H, Matsuyama Y, Tanaka E, et al. Risk factors contributing to early and late phase intrahepatic recurrence of hepatocellular carcinoma after hepatectomy. Journal of Hepatology. 2003; 38(2): 200-7. PMid: 12547409.

[37] Morimoto O, Nagano H, Sakon M, et al. Diagnosis of intrahepatic metastasis and multicentric carcinogenesis by microsatellite loss of heterozygosity in patients with multiple and recurrent hepatocellular carcinomas. Journal of Hepatology. 2003; 39(2): 215-21. PMid: 12873818.

[38] Schwartz JD, Schwartz M, Mandeli J, et al. Neoadjuvant and adjuvant therapy for resectable hepatocellular carcinoma: review of the randomised clinical trials. The Lancet Oncology. 2002; 3(10): 593-603. PMid: 12372721.

[39] Kumar M, Panda D. Role of supportive care for terminal stage hepatocellular carcinoma. Journal of clinical and experimental hepatology. 2014; 4(Suppl 3): S130-9. PMid: 25755605. http://dx.doi.org/10.1016/j.jceh.2014.03.049

[40] Barbara L, Benzi G, Gaiani S, et al. Natural history of small untreated hepatocellular carcinoma in cirrhosis: a multivariate analysis of prognostic factors of tumor growth rate and patient survival. Hepatology. 1992; 16(1): 132-7. PMid: 1352268.

[41] Chen MS, Li JQ, Zheng Y, et al. A prospective randomized trial comparing percutaneous local ablative therapy and partial hepatectomy for small hepatocellular carcinoma. Annals of surgery. 2006; 243(3): 321-8. PMid: 16495695. http://dx.doi.org/10.1097/01.sla.0000201480.65519.b8

[42] Cho YK, Kim JK, Kim WT, et al. Hepatic resection versus radiofrequency ablation for very early stage hepatocellular carcinoma: a Markov model analysis. Hepatology. 2010; 51(4): 1284-90. PMid: 20099299. http://dx.doi.org/10.1002/hep.23466

[43] Roberts JP, Venook A, Kerlan R, et al. Hepatocellular carcinoma: Ablate and wait versus rapid transplantation. Liver transplantation: official publication of the American Association for the Study of Liver Diseases and the International Liver Transplantation Society. 2010; 16(8): 925-9. PMid: 20658555. http://dx.doi.org/10.1002/1t.22103

[44] Lencioni R. Locoregional treatment of hepatocellular carcinoma. Hepatology. 2010; 52(2): 762-73. PMid: 20564355. http://dx.doi.org/10.1002/hep.23725

[45] Cho YK, Kim JK, Kim MY, et al. Systematic review of randomized trials for hepatocellular carcinoma treated with percutaneous ablation therapies. Hepatology. 2009; 49(2): 453-9. PMid: 19065676. http://dx.doi.org/10.1002/hep.22648

[46] Germani G, Pleguezuelo M, Gurusamy K, et al. Clinical outcomes of radiofrequency ablation, percutaneous alcohol and acetic acid injection for hepatocelullar carcinoma: a meta-analysis. Journal of hepatology. 2010; 52(3): 380-8. PMid: 20149473. http://dx.doi.org/10.1016/j.jhep.2009.12.004

[47] Peng ZW, Zhang YJ, Chen MS, et al. Radiofrequency ablation with or without transcatheter arterial chemoembolization in the treatment of hepatocellular carcinoma: a prospective randomized trial. Journal of Clinical Oncology: official journal of the American Society of Clinical Oncology. 2013; 31(4): 426-32. PMid: 23269991. http://dx.doi.org/10.1200/JCO.2012.42.9936

[48] Lin SM, Lin CJ, Lin CC, et al. Radiofrequency ablation improves prognosis compared with ethanol injection for hepatocellular carcinoma $<$ or $=4 \mathrm{~cm}$. Gastroenterology. 2004; 127(6): 1714-23. PMid: 15578509. 
[49] Lin SM, Lin CJ, Lin CC, et al. Randomised controlled trial comparing percutaneous radiofrequency thermal ablation, percutaneous ethanol injection, and percutaneous acetic acid injection to treat hepatocellular carcinoma of $3 \mathrm{~cm}$ or less. Gut. 2005; 54(8): 1151-6. PMid: 16009687. http://dx.doi.org/10.1136/gut.2004.045203

[50] Shiina S, Teratani T, Obi S, et al. A randomized controlled trial of radiofrequency ablation with ethanol injection for small hepatocellular carcinoma. Gastroenterology. 2005; 129(1): 122-30. PMid: 16012942.

[51] Lu DS, Yu NC, Raman SS, et al. Radiofrequency ablation of hepatocellular carcinoma: treatment success as defined by histologic examination of the explanted liver. Radiology. 2005; 234(3): 954-60. PMid: 15681691. http://dx.doi.org/10.1148/radiol.2343040153

[52] Kim SW, Rhim H, Park M, et al. Percutaneous radiofrequency ablation of hepatocellular carcinomas adjacent to the gallbladder with internally cooled electrodes: assessment of safety and therapeutic efficacy. Korean Journal of Radiology. 2009; 10(4): 366-76. PMid: 19568465. http://dx.doi.org/10.3348/kjr.2009.10.4.366

[53] Komorizono Y, Oketani M, Sako K, et al. Risk factors for local recurrence of small hepatocellular carcinoma tumors after a single session, single application of percutaneous radiofrequency ablation. Cancer. 2003; 97(5): 1253-62. PMid: 12599233. http://dx.doi.org/10.1002/cncr.11168

[54] Machi J, Bueno RS, Wong LL. Long-term follow-up outcome of patients undergoing radiofrequency ablation for unresectable hepatocellular carcinoma. World Journal of Surgery. 2005; 29(11): 1364-73. PMid: 16240062. http://dx.doi.org/10.1007/s00268-005-7829-6

[55] Kasugai H, Osaki Y, Oka H, et al. Severe complications of radiofrequency ablation therapy for hepatocellular carcinoma: an analysis of 3,891 ablations in 2,614 patients. Oncology. 2007; 72 Suppl 1: 72-5. PMid: 18087185. http://dx.doi.org/10.1159/000111710

[56] Lencioni R, Cioni D, Crocetti L, et al. Early-stage hepatocellular carcinoma in patients with cirrhosis: long-term results of percutaneous image-guided radiofrequency ablation. Radiology. 2005; 234(3): 961-7. PMid: 15665226. http://dx.doi.org/10.1148/radiol.2343040350

[57] Huang GT, Lee PH, Tsang YM, et al. Percutaneous ethanol injection versus surgical resection for the treatment of small hepatocellular carcinoma: a prospective study. Annals of Surgery. 2005; 242(1): 36-42. PMid: 15973099.

[58] Lencioni RA, Allgaier HP, Cioni D, et al. Small hepatocellular carcinoma in cirrhosis: randomized comparison of radiofrequency thermal ablation versus percutaneous ethanol injection. Radiology. 2003; 228(1): 235-40. PMid: 12759473. http://dx.doi.org/10.1148/radiol.2281020718

[59] Shibata T, Iimuro Y, Yamamoto Y, et al. Small hepatocellular carcinoma: comparison of radio-frequency ablation and percutaneous microwave coagulation therapy. Radiology. 2002; 223(2): 331-7. PMid: 11997534. http://dx.doi.org/10.1148/radiol.2232010775

[60] Brunello F, Veltri A, Carucci P, et al. Radiofrequency ablation versus ethanol injection for early hepatocellular carcinoma: A randomized controlled trial. Scandinavian journal of gastroenterology. 2008; 43(6): 727-35. PMid: 18569991. http://dx.doi.org/10.1080/00365520701885481

[61] Livraghi T, Bolondi L, Lazzaroni S, et al. Percutaneous ethanol injection in the treatment of hepatocellular carcinoma in cirrhosis. A study on 207 patients. Cancer. 1992; 69(4): 925-9. PMid: 1310435.

[62] Sala M, Llovet JM, Vilana R, et al. Initial response to percutaneous ablation predicts survival in patients with hepatocellular carcinoma. Hepatology. 2004; 40(6): 1352-60. PMid: 15565564. http://dx.doi.org/10.1002/hep.20465

[63] Lencioni R, Bartolozzi C, Caramella D, et al. Treatment of small hepatocellular carcinoma with percutaneous ethanol injection. Analysis of prognostic factors in 105 Western patients. Cancer. 1995; 76(10): 1737-46. PMid: 8625042.

[64] Khan KN, Yatsuhashi H, Yamasaki K, et al. Prospective analysis of risk factors for early intrahepatic recurrence of hepatocellular carcinoma following ethanol injection. Journal of Hepatology. 2000; 32(2): 269-78. PMid: 10707867.

[65] Orlacchio A, Bazzocchi G, Pastorelli D, et al. Percutaneous cryoablation of small hepatocellular carcinoma with US guidance and CT monitoring: initial experience. Cardiovascular and interventional radiology. 2008; 31(3): 587-94. PMid: 18236104. http://dx.doi.org/10.1007/s00270-008-9293-9

[66] Pacella CM, Francica G, Di Lascio FM, et al. Long-term outcome of cirrhotic patients with early hepatocellular carcinoma treated with ultrasound-guided percutaneous laser ablation: a retrospective analysis. Journal of Clinical Oncology: official journal of the American Society of Clinical Oncology. 2009; 27(16): 2615-21. PMid: 19332729. http://dx.doi.org/10.1200/JCO.2008.19.0082

[67] Lencioni R, Llovet JM. Modified RECIST (mRECIST) assessment for hepatocellular carcinoma. Seminars in liver disease. 2010; 30(1): 52-60. PMid: 20175033. http://dx.doi.org/10.1055/s-0030-1247132

[68] Llovet JM, Bruix J. Systematic review of randomized trials for unresectable hepatocellular carcinoma: Chemoembolization improves survival. Hepatology. 2003; 37(2): 429-42. PMid: 12540794. http://dx.doi.org/10.1053/jhep.2003.50047 
[69] Llovet JM, Ricci S, Mazzaferro V, et al. Sorafenib in advanced hepatocellular carcinoma. The New England journal of medicine. 2008; 359(4): 378-90. PMid: 18650514. http://dx.doi.org/10.1056/NEJMoa0708857

[70] Varela M, Real MI, Burrel M, et al. Chemoembolization of hepatocellular carcinoma with drug eluting beads: efficacy and doxorubicin pharmacokinetics. Journal of Hepatology. 2007; 46(3): 474-81. PMid: 17239480. http://dx.doi.org/10.1016/j.jhep.2006.10.020

[71] Lammer J, Malagari K, Vogl T, et al. Prospective randomized study of doxorubicin-eluting-bead embolization in the treatment of hepatocellular carcinoma: results of the PRECISION V study. Cardiovascular and interventional radiology. 2010; 33(1): 41-52. PMid: 19908093. http://dx.doi.org/10.1007/s00270-009-9711-7

[72] Burrel M, Reig M, Forner A, et al. Survival of patients with hepatocellular carcinoma treated by transarterial chemoembolisation (TACE) using Drug Eluting Beads. Implications for clinical practice and trial design. Journal of Hepatology. 2012; 56(6): 1330-5. PMid: 22314428. http://dx.doi.org/10.1016/j.jhep.2012.01.008

[73] Malagari K, Pomoni M, Moschouris H, et al. Chemoembolization with doxorubicin-eluting beads for unresectable hepatocellular carcinoma: five-year survival analysis. Cardiovascular and interventional radiology. 2012; 35(5): 1119-28. PMid: 22614031. http://dx.doi.org/10.1007/s00270-012-0394-0

[74] Cabibbo G, Genco C, Di Marco V, et al. Predicting survival in patients with hepatocellular carcinoma treated by transarterial chemoembolisation. Alimentary Pharmacology \& Therapeutics. 2011; 34(2): 196-204. PMid: 21564144. http://dx.doi.org/10.1111/j.1365-2036.2011.04694.x

[75] Dhanasekaran R, Kooby DA, Staley CA, et al. Prognostic factors for survival in patients with unresectable hepatocellular carcinoma undergoing chemoembolization with doxorubicin drug-eluting beads: a preliminary study. HPB: the official journal of the International Hepato Pancreato Biliary Association. 2010; 12(3): 174-80. PMid: 20590884.

http://dx.doi.org/10.1111/j.1477-2574.2009.00138.x

[76] Bolondi L, Burroughs A, Dufour JF, et al. Heterogeneity of patients with intermediate (BCLC B) Hepatocellular Carcinoma: proposal for a subclassification to facilitate treatment decisions. Seminars in Liver Disease. 2012; 32(4): 348-59. PMid: 23397536. http://dx.doi.org/10.1055/s-0032-1329906

[77] Raoul JL, Sangro B, Forner A, et al. Evolving strategies for the management of intermediate-stage hepatocellular carcinoma: available evidence and expert opinion on the use of transarterial chemoembolization. Cancer Treat Rev. 2011; 37(3): 212-20. PMid: 20724077. http://dx.doi.org/10.1016/j.ctrv.2010.07.006

[78] Salem R, Mazzaferro V, Sangro B. Yttrium 90 radioembolization for the treatment of hepatocellular carcinoma: biological lessons, current challenges, and clinical perspectives. Hepatology. 2013; 58(6): 2188-97. PMid: 23512791. http://dx.doi.org/10.1002/hep.26382

[79] Rougier P, Mitry E, Barbare JC, et al. Hepatocellular carcinoma (HCC): an update. Seminars in oncology. 2007; 34(2 Suppl 1): S12-20. PMid: 17449346. http://dx.doi.org/ 10.1053/j.seminoncol.2007.01.007

[80] Taieb J, Barbare JC, Rougier P. Medical treatments for hepatocellular carcinoma (HCC): what's next? Annals of oncology: official journal of the European Society for Medical Oncology / ESMO. 2006; 17 Suppl 10: x308-14. PMid: 17018744. http://dx.doi.org/10.1093/annonc/mdl279

[81] Nowak AK, Chow PK, Findlay M. Systemic therapy for advanced hepatocellular carcinoma: a review. European journal of cancer. 2004; 40(10): 1474-84. PMid: 15196530. http://dx.doi.org/10.1016/j.ejca.2004.02.027

[82] Deng GL, Zeng S, Shen H. Chemotherapy and target therapy for hepatocellular carcinoma: New advances and challenges. World journal of hepatology. 2015; 7(5): 787-98. PMid: 25914779. http://dx.doi.org/10.4254/wjh.v7.i5.787

[83] Arii S, Sata M, Sakamoto M, et al. Management of hepatocellular carcinoma: Report of Consensus Meeting in the 45th Annual Meeting of the Japan Society of Hepatology (2009). Hepatology research: the official journal of the Japan Society of Hepatology. 2010; 40(7): 667-85. PMid: 20633193. http://dx.doi.org/10.1111/j.1872-034X.2010.00673.x

[84] Hollebecque A, Cattan S, Romano O, et al. Safety and efficacy of sorafenib in hepatocellular carcinoma: the impact of the ChildPugh score. Alimentary pharmacology \& therapeutics. 2011; 34(10): 1193-201. PMid: 21958438. http://dx.doi.org/10.1111/j.1365-2036.2011.04860.x

[85] Kim JE, Ryoo BY, Ryu MH, et al. Sorafenib for hepatocellular carcinoma according to Child-Pugh class of liver function. Cancer chemotherapy and pharmacology. 2011; 68(5): 1285-90. PMid: 21445543. http://dx.doi.org/10.1007/s00280-011-1616-x

[86] Wang SN, Chuang SC, Lee KT. Efficacy of sorafenib as adjuvant therapy to prevent early recurrence of hepatocellular carcinoma after curative surgery: A pilot study. Hepatology research: the official journal of the Japan Society of Hepatology. 2014; 44(5): 523-31. PMid: 23672310. http://dx.doi.org/10.1111/hepr.12159

[87] Vitale A, Volk ML, Pastorelli D, et al. Use of sorafenib in patients with hepatocellular carcinoma before liver transplantation: a cost-benefit analysis while awaiting data on sorafenib safety. Hepatology. 2010; 51(1): 165-73. PMid: 19877181. http://dx.doi.org/10.1002/hep.23260 
[88] Kulik L, Vouche M, Koppe S, et al. Prospective randomized pilot study of Y90+/-sorafenib as bridge to transplantation in hepatocellular carcinoma. Journal of Hepatology. 2014; 61(2): 309-17. PMid: 24681342. http://dx.doi.org/10.1016/j.jhep.2014.03.023

[89] Truesdale AE, Caldwell SH, Shah NL, et al. Sorafenib therapy for hepatocellular carcinoma prior to liver transplant is associated with increased complications after transplant. Transplant international: official journal of the European Society for Organ Transplantation. 2011; 24(10): 991-8. PMid: 21777298. http://dx.doi.org/10.1111/j.1432-2277.2011.01299.x

[90] Kudo M, Imanaka K, Chida N, et al. Phase III study of sorafenib after transarterial chemoembolisation in Japanese and Korean patients with unresectable hepatocellular carcinoma. European Journal of Cancer. 2011; 47(14): 2117-27. PMid: 21664811. http://dx.doi.org/10.1016/j.ejca.2011.05.007

[91] Lencioni R, de Baere T, Burrel M, et al. Transcatheter treatment of hepatocellular carcinoma with Doxorubicin-loaded DC Bead (DEBDOX): technical recommendations. Cardiovascular and Interventional Radiology. 2012; 35(5): 980-5. PMid: 22009576. http://dx.doi.org/10.1007/s00270-011-0287-7

[92] Sansonno D, Lauletta G, Russi S, et al. Transarterial chemoembolization plus sorafenib: a sequential therapeutic scheme for HCV-related intermediate-stage hepatocellular carcinoma: a randomized clinical trial. The oncologist. 2012; $17(3)$ : $359-66$. PMid: 22334456. http://dx.doi.org/10.1634/theoncologist.2011-0313

[93] Strebel BM, Dufour JF. Combined approach to hepatocellular carcinoma: a new treatment concept for nonresectable disease. Expert review of anticancer therapy. 2008; 8(11): 1743-9. PMid: 18983234. http://dx.doi.org/10.1586/14737140.8.11.1743

[94] Mulcahy MF. Management of hepatocellular cancer. Current treatment options in oncology. 2005; 6(5): 423-35. PMid: 16107245.

[95] Asnacios A, Fartoux L, Romano O, et al. Gemcitabine plus oxaliplatin (GEMOX) combined with cetuximab in patients with progressive advanced stage hepatocellular carcinoma: results of a multicenter phase 2 study. Cancer. 2008; 112(12): 2733-9. PMid: 18412149. http://dx.doi.org/10.1002/cncr.23489

[96] Louafi S, Boige V, Ducreux M, et al. Gemcitabine plus oxaliplatin (GEMOX) in patients with advanced hepatocellular carcinoma (HCC): results of a phase II study. Cancer. 2007; 109(7): 1384-90. PMid: 17330837. http://dx.doi.org/10.1002/cncr.22532

[97] Taieb J, Bonyhay L, Golli L, et al. Gemcitabine plus oxaliplatin for patients with advanced hepatocellular carcinoma using two different schedules. Cancer. 2003; 98(12): 2664-70. PMid: 14669287. http://dx.doi.org/10.1002/cncr.11869

[98] Gish RG, Porta C, Lazar L, et al. Phase III randomized controlled trial comparing the survival of patients with unresectable hepatocellular carcinoma treated with nolatrexed or doxorubicin. Journal of clinical oncology: official journal of the American Society of Clinical Oncology. 2007; 25(21): 3069-75. PMid: 17634485. http://dx.doi.org/10.1200/JCO.2006.08.4046

[99] Lopez PM, Villanueva A, Llovet JM. Systematic review: evidence-based management of hepatocellular carcinoma--an updated analysis of randomized controlled trials. Alimentary pharmacology \& therapeutics. 2006; 23(11): 1535-47. PMid: 16696801. http://dx.doi.org/10.1111/j.1365-2036.2006.02932.x

[100] Yeo W, Mok TS, Zee B, et al. A randomized phase III study of doxorubicin versus cisplatin/interferon alpha-2b/doxorubicin/ fluorouracil (PIAF) combination chemotherapy for unresectable hepatocellular carcinoma. Journal of the National Cancer Institute. 2005; 97(20): 1532-8. PMid: 16234567. http://dx.doi.org/10.1093/jnci/dji315

[101] Abou-Alfa GK, Johnson P, Knox JJ, et al. Doxorubicin plus sorafenib vs doxorubicin alone in patients with advanced hepatocellular carcinoma: a randomized trial. Jama. 2010; 304(19): 2154-60. PMid: 21081728. http://dx.doi.org/10.1001/jama.2010.1672

[102] Prete SD, Montella L, Caraglia M, et al. Sorafenib plus octreotide is an effective and safe treatment in advanced hepatocellular carcinoma: multicenter phase II So.LAR. Study. Cancer chemotherapy and pharmacology. 2010; 66(5): 837-44. PMid: 20041325. http://dx.doi.org/10.1007/s00280-009-1226-z

[103] Yau T, Chan P, Ng KK, et al. Phase 2 open-label study of single-agent sorafenib in treating advanced hepatocellular carcinoma in a hepatitis B-endemic Asian population: presence of lung metastasis predicts poor response. Cancer. 2009; 115(2): 428-36. PMid: 19107763. http://dx.doi.org/10.1002/cncr.24029

[104] Hsu CH, Shen YC, Lin ZZ, et al. Phase II study of combining sorafenib with metronomic tegafur/uracil for advanced hepatocellular carcinoma. Journal of Hepatology. 2010; 53(1): 126-31. PMid: 20416968. http://dx.doi.org/10.1016/j.jhep.2010.01.035

[105] Giuliana FAR, et al. Sorafenib plus cisplatin and gemcitabine in the treatment of advanced hepatocellular carcinoma: a phase II study by the Grupo Oncologico Dell'Italia Meridonale. Cancer treatment reviews. 2010; 36(4 Suppl): S96. 